\title{
PYR/PYL/RCAR Abscisic Acid Receptors Regulate Root Cell hydraulic Conductivity through Activating Aquaporin expression
}

\author{
Xiaolin Wang $^{1 *}$, Ningning Zhang ${ }^{1 *} \&$ Jiakun Yan ${ }^{1}$ \\ ${ }^{1}$ College of Life Science, Yulin University, Yulin, 719000, China \\ Correspondence: Jiakun Yan, College of Life Science, Yulin University, Yulin, 719000, China. E-mail: \\ himingse@163.com \\ * These authors contributed equally to this work
}

Received: March 20, 2018

Accepted: April 9, 2018

Online Published: April 16, 2018

doi:10.5539/ijb.v10n3p7

URL: https://doi.org/10.5539/ijb.v10n3p7

\begin{abstract}
With a varied physical environment, plants have developed specific mechanisms that allow them to rapidly perceive and respond to stresses in the environment. As one of many pathways conserved in a long time evolution, the abscisic acid (ABA) signaling pathway has been identified as a central regulator to control gene expression and generate physiological adaptation to various stressful conditions in plant. As abscisic acid receptors, PYR/PYL/RCARs have been proved to regulate stomatal closure. Here we detected the root cell hydraulic conductivity and the aquaporin expression under treatment of exogenous $\mathrm{ABA}$ in wild-type and pyr1/pyl1/pyl2/pyl4 mutant Arabidopsis using cell pressure probe and qRT-PCR technology. The results showed that PYR/PYL/RCAR receptors regulate root cell hydraulic conductivity through activating aquaporin expression. Lastly, we discussed how plants maintain water balance combined with the data obtained from published articles.
\end{abstract}

Keywords: PYR/PYL/RCAR Receptors, Root cell hydraulic conductivity, Aquaporin, Abscisic acid

\section{Introduction}

Plants are exposed to several stressful conditions, and water deficit is one of the most common abiotic stresses, which causes severe and even irreversible damage. The effects of water deficit are becoming more and more serious with global climate change and growing water scarcity. Water is an increasingly scarce resource given current and future human population and societal needs, putting an emphasis on sustainable water use (Harb, Krishnan, Ambavaram, \& Pereira, 2010). Therefore, in-depth understanding of relation between plant water use and water deficit is necessary for the sustainable development of agriculture.

Plant growth in natural environment depends on an optimum balance between roots water uptake and water losses through the shoots (W. Wang, Yang, Zhang, \& Sun, 2013). Water uptake by roots, which provides the original water source for whole-plant water balance, plays a vital role in maintaining the plant water balance especially in water deficit condition. According to Heinen (Heinen, Ye, \& Chaumont, 2009), water moves across plant tissues through both apoplastic and cell-to-cell path-ways. The cell-to-cell pathway refers to water flow through the plasmodesmata and/or across membranes, substantially contributing to whole-plant hydraulic resistance. Root hydraulic conductivity represents the ability of plant absorbing water. Root hydraulic conductivity can be divided into three levels: root system $\left(\mathrm{Lp}_{\mathrm{rs}}\right)$, individual root $\left(\mathrm{Lp}_{\mathrm{r}}\right)$ and root cell $\left(\mathrm{Lp}_{\mathrm{rc}}\right)$ hydraulic conductivity. Aquaporins located in the plasma membrane (plasma membrane intrinsic proteins, PIPs) affect the water trans-membrane movement significantly (Postaire et al., 2010; Qian, Song, Chaumont, \& Ye, 2014).

A numerous of studies has showed ABA is involved plant responses to abiotic stresses such as cold, drought, and salinity as well as the regulation of plant growth and development, including embryogenesis, seed dormancy, shoot and root growth, and leaf transpiration (Acharya, Jeon, Zhang, \& Assmann, 2013; Chen, Yang, Lur, Tsai, \& Chang, 2006; Kempa, Krasensky, Dal Santo, Kopka, \& Jonak, 2008; Pantin et al., 2013; Tardieu, Parent, \& Simonneau, 2010; Xiong, Ishitani, Lee, \& Zhu, 2001; Zhu, Schraut, Hartung, \& Schäffner, 2005). Under water deficit stress, ABA content increases in leaves inducing stomatal closure that decreases the rate of transpiration and stomatal conductance. In this process, a basic core of $\mathrm{ABA}$ signaling that involves an $\mathrm{ABA}$ receptor complex, consisting of an ABA receptor family (PYR/PYL/RCAR), protein phosphatases 2C (PP2C) and Snf1-related protein kinase 2s (SnRK2s), induces a variety of molecular events in plant cells(Osakabe, Yamaguchi-Shinozaki, Shinozaki, \& Tran, 2014). PYR/PYL/RCAR receptors constitute a 14-member family, almost all of which are able to activate $\mathrm{ABA}-$-responsive gene expression in protoplast transfection assays and six PYR/PYL receptors, namely 
PYR1, PYL1, PYL2, PYL4, PYL5, and PYL8, is able to germinate and grow even on $100 \mu \mathrm{M}$ ABA (Fujii et al., 2009; M. Gonzalez-Guzman et al., 2012). PYR/PYL/RCAR receptors play a major role in regulating stomatal aperture and transcriptional response to abscisic acid in Arabidopsis (M. Gonzalez-Guzman et al., 2012; Y. Wang, Chen, Zhang, Hills, \& Blatt, 2013). However, whether PYR/PYL/RCAR receptors take part in roots water uptake, and if it have affected this process, how it works?

In this study, we examined the hypothesis that in plant PYR/PYL/RCAR receptors regulate root cell hydraulic conductivity through activating aquaporin expression. We detected the root cell hydraulic conductivity and the aquaporin expression under treatment of ABA in wild-type and pyr1/pyl1/pyl2/pyl4 mutant Arabidopsis. We also analyzed the relationship between them. Lastly, based on our data and information obtained from published articles, a possible model PYR/PYL/RCAR receptors involved in maintaining whole plant water balance was written for a better understanding.

\section{Materials and Methods}

\subsection{Plant Growth and Preparation}

Wild-type Arabidopsis (Arabidopsis thaliana ecotype Columbia ) and the pyr1/pyl1/pyl2/pyl4 quadruple mutant Qm were sown in Murashige and Skoog medium(Murashige \& Skoog, 1962) for 10 days and then transplanted to a quarter Hoagland nutrient solution grown under a 12-h/12-h day/night cycle $\left(300 \mu \mathrm{mol}\right.$ photons $\left.\mathrm{m}^{-2} \mathrm{~s}^{-1}\right)$ and $60 \%$ humidity in the growth chambers (AGC-D001P, Qiushi Corp., Hangzhou, China). After two weeks, third of the plants were transplanted to the $1 / 4$ Hoagland solution containing ABA (final concentration $=1000 \mathrm{~nm}$ ), third in containing $\mathrm{ABA}$ (final concentration=100nm), and the remaining plants, as controls, continued to grow in the $1 / 4$ Hoagland solution without ABA. So this study had three treatments: controls and ABA stressed plants. After the 0 , half and one hour of the treatment, three treatment plants were used to measure cell hydraulic parameters. Only the controls and $1000 \mathrm{~nm}$ treated plants were collected immediately immersed in liquid nitrogen and stored at $-80{ }^{\circ} \mathrm{C}$.

\subsection{Quantitative Real-Time PCR}

Total RNA was extracted from the samples using an RNAprep pure Plant Kit (TIANGEN, Beijing, China). The RNA extract was digested with DNase I and examined using a dissociation curve to ensure that DNA was eliminated. The cDNA was synthesized in vitro using a TIANScript RT Kit (TIANGEN, Beijing, China) according to the manufacturer's instructions. The quantitative real-time PCR was carried out according to Jang's Method (Jang, D. G. Kim, Y. O. Kim, J. S. Kim, \& Kang, 2004). Based on Jang's result, we selected 5 AtPIP genes (AtPIP1;1,AtPIP1;2,AtPIP1;4,AtPIP2;1 and AtPIP2;6) to detect.

\subsection{Measurements of Cell Hydraulic Parameters}

Cell pressure probe (CPP) was employed to meter cell hydraulic parameters. Method used in this procedure was referred to Javot (Javot et al., 2003)and Qian(Qian et al., 2014).

\subsection{Statistical Analyses}

Statistical analyses were performed with the SPSS version13.0. The correlation and regression analyses were conducted using SigmaPlot version 12.01 (Systat Software; http://www.sigmaplot.com).

\section{Results}

\subsection{Cell Hydraulic Parameters Measurements}

For controls, the half time ( $\mathrm{T}_{1 / 2}$ ) of hydrostatic water flow across cell membrane ranged from 1.76 to $3.05 \mathrm{~s}$ (Figure 1A). Under $A B A$ treatment in wild-type, both $100 \mathrm{~nm}$ and $1000 \mathrm{~nm}, \mathrm{~T}_{1 / 2}$ significantly reduced (25\%-78\%), while in the $\mathrm{Qm}$ mutant it remains unchanged (Figure 1A). With the difference in $\mathrm{T}_{1 / 2}$, the root cell hydraulic conductivity $\left(\mathrm{Lp}_{\mathrm{rc}}\right.$ ) varied in those two treatments. With $1000 \mathrm{~nm} A B A$ treatment $1 \mathrm{~h}$, the $\mathrm{L} \mathrm{p}_{\mathrm{rc}}$ increased to $5.51 \times 10^{-6} \mathrm{~ms}^{-1} \mathrm{MPa}^{-1}$, which was $81 \%$ higher than controls. It was no surprises that under two different $\mathrm{ABA}$ concentrations treatments, the $\mathrm{Lp}_{\mathrm{rc}}$ of $\mathrm{Qm}$ had no statistical change compared to controls (Figure 1B).

\subsection{Changes in AtPIP mRNA Levels in Response to ABA Treatment}

PIPs have been identified and proved to influence the root hydraulic conductivity. To obtain evidence that some of these genes were regulated by PYR/PYL/RCAR receptors, we measured relative expression of 5 AtPIP genes in roots by quantitative real-time PCR. The qRT-PCR analyses with gene specific primers (Figure 2) revealed that these 5 AtPIP genes were expressed in roots of these two Arabidopsis. Of those genes, AtPIP1;1, AtPIP1;2 and AtPIP2; 6 were significantly increased in wild-type after using $1000 \mathrm{~nm}$ ABA treatment. Nevertheless, these 5 AtPIPs had no discernible influence in mutant $\mathrm{Qm}$ before or after the treatment with exogenous ABA.

To confirm whether it has correlation between $L p_{\mathrm{rc}}$ and the relative expression of $A t P I P \mathrm{~s}$, we make correlation analysis. The results showed significantly positive relationship between $\mathrm{Lp}_{\mathrm{rc}}$ and AtPIP1;1 $\left(\mathrm{R}^{2}=0.9502 ; \mathrm{P}=0.0009\right)$ and AtPIP2; $6\left(\mathrm{R}^{2}=0.9592 ; \mathrm{P}=0.0006\right)$ (Figure 3). 

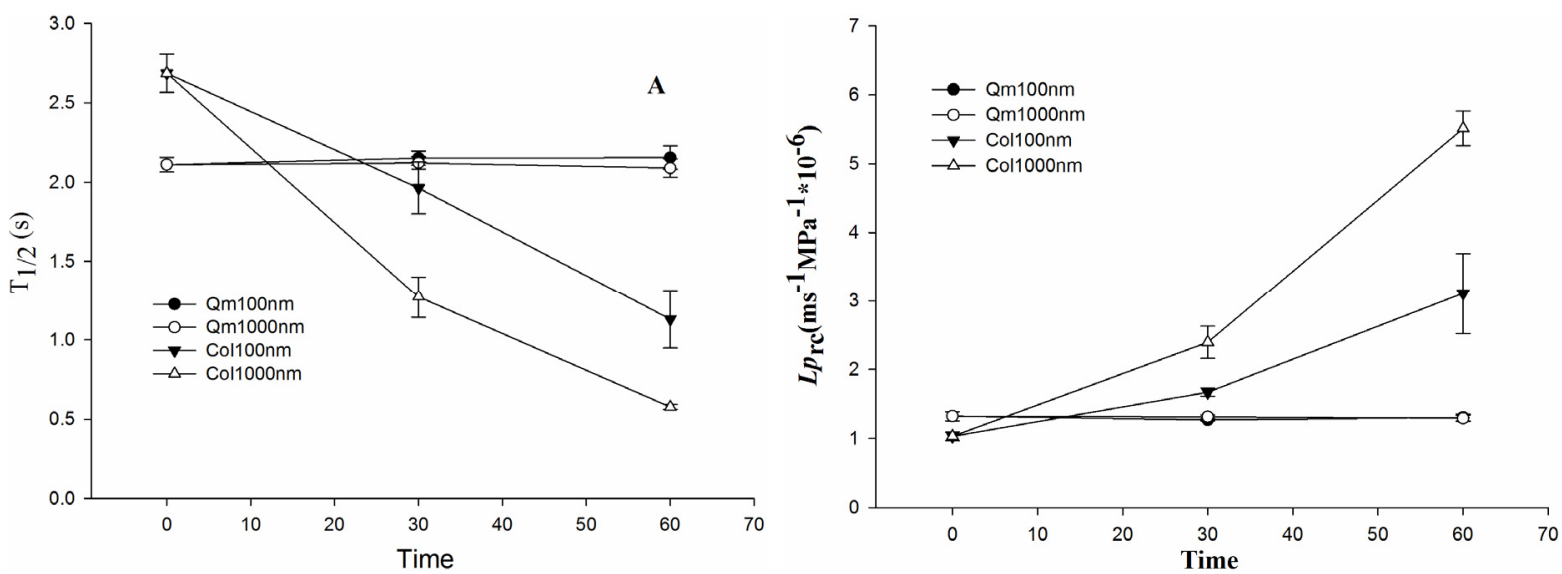

Figure 1. the half time (T1/2) of hydrostatic water flow across cell membrane and root cell (A) and root cell hydraulic conductivities (B) in mutant $\mathrm{Qm}$ and wild type Col. X axis represents time duration of ABA treatment $(0,30 \mathrm{~min}$ and $60 \mathrm{~min})$. Data are mean $\pm \mathrm{SD}$ ( $\mathrm{n}=6$ to 8 plants $)$

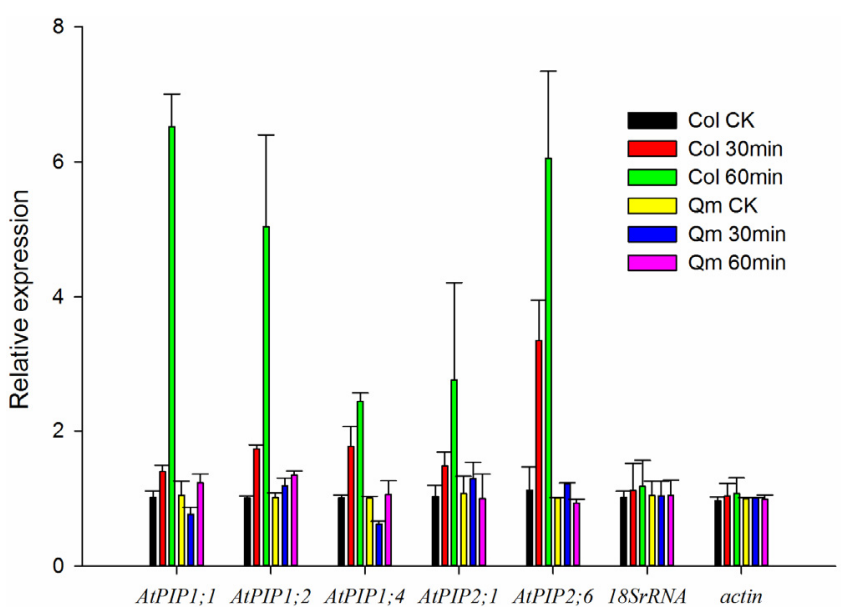

Figure 2. Relative expression of 5 AtPIP genes in roots from plants treated with exogenous ABA(Col-wild type;Qm-mutant). Gene expressions were determined by quantitative real-time PCR, and the geometric mean of the expression levels of three reference genes were used to normalize data. $\mathrm{X}$ axis represents 10 AtPIPs and three reference genes. Results are shown as relative changes of gene expression of ABA-treated plants to that of control plants. Different letters above columns represent a significant differences between stress-treated and control plants $($ mean $\pm \mathrm{SD} ; \mathrm{P}<0.05)$
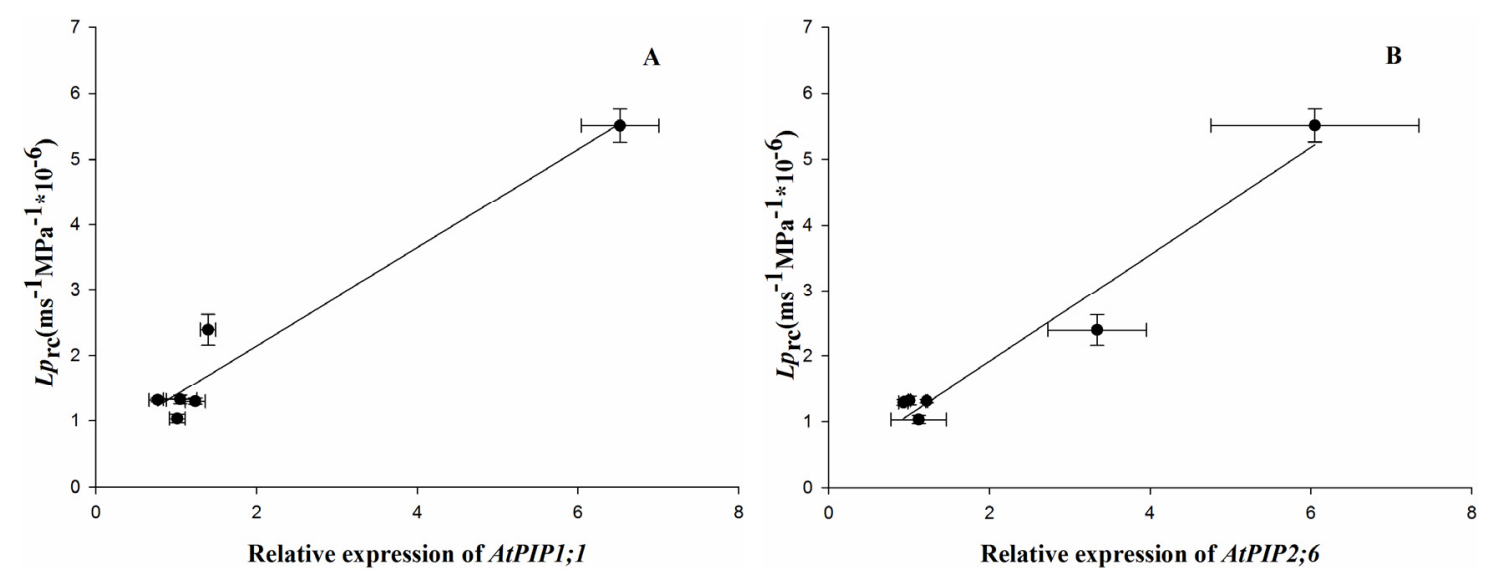

Figure 3. Root cell hydraulic conductivity (Lprc) is positively correlated with the relative expression of AtPIPI; 1(A) and AtPIP2; 6(B), respectively, in the roots. Points are the mean of parameters and error bars represent the S.D. (Lprc, $\mathrm{n}=11-15$; relative expression, $\mathrm{n}=3$ ). The correlation analyses were performed using SigmaPlot version 12.01, and the relation coefficient (R2) and significant level (P) are shown 


\section{Discussion}

Arabidopsis PYR/PYL/RCAR receptors have been extensively studied in regulation of stomatal aperture and the mechanism since it was identified (Fujii et al., 2009; M. Gonzalez-Guzman et al., 2012). We investigated PYR/PYL/RCAR receptors' effect on root water uptake and the expression of AtPIPs. Based on our data and some others obtained from previous studies, some questions or hypotheses that related to whole-plant water balance were discussed here.

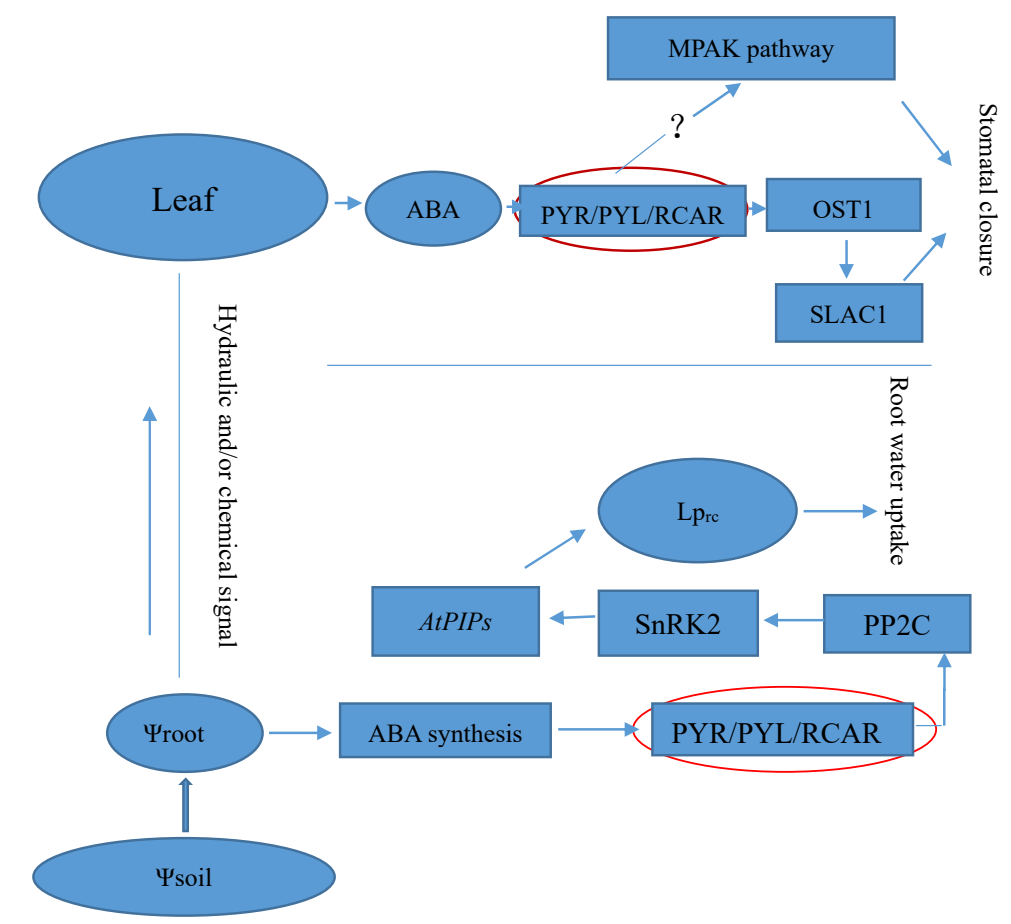

Figure 4. A possible model for PYR/PYL/RCAR receptors control whole-plant water balance. In water deficit status, root water potentials decrease. As a result, ABA content increase. Along the ABA signaling pathway, abundance of PIPs increases. Root cell hydraulic conductivity enhances. At the same time, root signaling transmits to leaf. In leaf, ABA accumulates. Lastly, stomata is closed and water loss by transpiration reduces

\subsection{ABA Involved in Root Water Uptake}

Root hydraulic conductivity is the most important part in water uptake from soil and loss into air by transpiration (Vandeleur et al., 2009). Mahdieh shows that ABA facilitates the root hydraulic conductivity by aquaporin expression in Nicotiana tabacum(Mahdieh \& Mostajeran, 2009). And many other researches have demonstrated ABA facilitates the uptake of water by roots (Christmann, Weiler, Steudle, \& Grill, 2007; Kudoyarova et al., 2011). Our data showed that exogenous ABA accelerated the root cell hydraulic conductivity. This result is consistent with Beaudette's study in Pisum sativum (Beaudette, Chlup, Yee, \& Emery, 2007). And more in that study, they also found PSPIP2-1 expression in lateral roots was strongly correlated with diurnal changes in $\mathrm{Lp}_{\mathrm{r}}$, which is consistent to our results (Figure 3). So those results indicated that ABA was involved in regulating root water uptake.

\subsection{PYR/PYL/RCAR Receptors Involved in ABA Regulated Root Cell Hydraulic Conductivity}

$\mathrm{PYR} / \mathrm{PYL} / \mathrm{RCAR}$ receptors have the potential applications in enhancing plant drought resistance (Miguel Gonzalez-Guzman et al., 2014; Kim et al., 2014; Pizzio et al., 2013). Overexpression of PYL5 in rice modulates gene expression, most of which are associated with metabolic processes, cellular processes, and response to stress. And Overexpression of PYL5 in rice enhances drought tolerance(Kim et al., 2014). In our research, Qm mutant was insensitive to exogenous $\mathrm{ABA}$ both in $\mathrm{L}_{\mathrm{rc}}$ and AtPIPs expression (Figure 1 and Figure 2). It indicates that ABA involved in toot hydraulic conductivity maybe functions by PYR/PYL/RCAR signaling pathway. According to Jang's research, control the expression of AtPIP 1;2 was regulated by ABA-dependent signaling pathway under environmental stress. Combining with our data, we hold that ABA regulates AtPIP1;2 expression via PYR/PYL/RCAR receptors. 


\subsection{A Possible Model for PYR/PYL/RCAR Receptors Control Plant Water Balance}

Based on our results and information from the literatures, a possible model for PYR/PYL/RCAR receptors control whole-plant water balance was proposed here (Figure 4). Under drought stress, soil water potential $\left(\Psi_{\text {soil }}\right)$ decreases, which induces Root or xylem water potentials decreases. With root water potentials decreasing, root ABA synthesis is started. Soon, PYR/PYL/RCAR receptors receipt ABA signal, then active PP2Cs to phosphorylate SnRK2 and lastly regulate AtPIPs expression in root. As a physiological response, root cell hydraulic conductivity increases and root water uptake is enhanced. At the same time, root hydraulic and/or chemical signal transmits to leaf (Christmann et al., 2007; Comstock, 2002). Later, ABA content in leaf increases. PYR/PYL/RCAR receptors regulates OST1 (Open stomata 1, protein kinase) and SLAC1 controlling ion in or out of guard cells (Acharya et al., 2013; Danquah, de Zelicourt, Colcombet, \& Hirt, 2014; Mustilli, Merlot, Vavasseur, Fenzi, \& Giraudat, 2002). And another side, according to Gonzalez's data (M. Gonzalez-Guzman et al., 2012), the expressions of MAPK genes in PYR/PYL/RCAR mutant are lower than those in wild-type Col. So maybe MAPK pathways is partly regulated by PYR/PYL/RCAR receptors. And MAPK pathways take part in stomatal movement(Des Marais et al., 2014). All these responses induce stomatal closure. So water loss by transpiration decreases. All these data show that the PYR/PYL/RCAR receptors play a crucial role in controlling water in or out of plant.

\section{Acknowledge}

We thank Dr. Wu Biao from Yellow Sea Fishery Research Institute for his help in RT-PCR and Dr. Zhang Jingyuan from NWAFU for her help in CPP. We also thank those authors of articles we cited for their excellent jobs in ABA pathway.

\section{Reference}

Acharya, B. R., Jeon, B. W., Zhang, W., \& Assmann, S. M. (2013). Open Stomata 1 (OST1) is limiting in abscisic acid responses of Arabidopsis guard cells. New Phytologist, 200(4), 1049-1063. https://doi.org/ 10.1111/nph.12469

Beaudette, P. C., Chlup, M., Yee, J., \& Emery, R. J. (2007). Relationships of root conductivity and aquaporin gene expression in Pisum sativum: diurnal patterns and the response to $\mathrm{HgCl} 2$ and ABA. J Exp Bot, 58(6), 1291-1300. https://doi.org/10.1093/jxb/erl289

Chen, C. W., Yang, Y. W., Lur, H. S., Tsai, Y. G., \& Chang, M. C. (2006). A novel function of abscisic acid in the regulation of rice (Oryza sativa L.) root growth and development. Plant Cell Physiol, 47(1), 1-13. https://doi.org/10.1093/pcp/pci216

Christmann, A., Weiler, E. W., Steudle, E., \& Grill, E. (2007). A hydraulic signal in root-to-shoot signalling of water shortage. Plant J, 52(1), 167-174. https://doi.org/10.1111/j.1365-313X.2007.03234.x

Comstock, J. P. (2002). Hydraulic and chemical signalling in the control of stomatal conductance and transpiration. J Exp Bot, 53(367), 195-200. https://doi.org/10.1093/jexbot/53.367.195

Danquah, A., de Zelicourt, A., Colcombet, J., \& Hirt, H. (2014). The role of ABA and MAPK signaling pathways in plant abiotic stress responses. Biotechnology Advances, 32(1), 40-52. http://dx.doi.org/10. 1016/j.biotechadv.2013.09.006

Des Marais, D. L., Auchincloss, L. C., Sukamtoh, E., McKay, J. K., Logan, T., Richards, J. H., \& Juenger, T. E. (2014). Variation in MPK12 affects water use efficiency in Arabidopsis and reveals a pleiotropic link between guard cell size and ABA response. Proceedings of the National Academy of Sciences, 111(7), 2836-2841. https://doi.org/10.1073/pnas.1321429111

Fujii, H., Chinnusamy, V., Rodrigues, A., Rubio, S., Antoni, R., Park, S. Y., ... Zhu, J. K. (2009). In vitro reconstitution of an abscisic acid signalling pathway. Nature, 462(7273), 660-664. https://doi.org/10. 1038/nature08599

Gonzalez-Guzman, M., Pizzio, G. A., Antoni, R., Vera-Sirera, F., Merilo, E., Bassel, G. W., ... Rodriguez, P. L. (2012). Arabidopsis PYR/PYL/RCAR receptors play a major role in quantitative regulation of stomatal aperture and transcriptional response to abscisic acid. Plant Cell, 24(6), 2483-2496. https://doi.org/ $10.1105 /$ tpc. 112.098574

Gonzalez-Guzman, M., Rodriguez, L., Lorenzo-Orts, L., Pons, C., Sarrion-Perdigones, A., Fernandez, M. A., ... Rodriguez, P. L. (2014). Tomato PYR/PYL/RCAR abscisic acid receptors show high expression in root, differential sensitivity to the abscisic acid agonist quinabactin, and the capability to enhance plant drought resistance. $J$ Exp Bot. https://doi.org/10.1093/jxb/eru219 
Harb, A., Krishnan, A., Ambavaram, M. M., \& Pereira, A. (2010). Molecular and physiological analysis of drought stress in Arabidopsis reveals early responses leading to acclimation in plant growth. Plant Physiol, 154(3), 1254-1271. https://doi.org/10.1104/pp.110.161752

Heinen, R. B., Ye, Q., \& Chaumont, F. (2009). Role of aquaporins in leaf physiology. J Exp Bot, 60(11), 2971-2985. https://doi.org/10.1093/jxb/erp171

Jang, J. Y., Kim, D. G., Kim, Y. O., Kim, J. S., \& Kang, H. (2004). An expression analysis of a gene family encoding plasma membrane aquaporins in response to abiotic stresses in Arabidopsis thaliana. Plant Mol Biol, 54(5), 713-725. https://doi.org/10.1023/B:PLAN.0000040900.61345.a6

Javot, H., Lauvergeat, V., Santoni, V., Martin-Laurent, F., Guclu, J., Vinh, J., ... Maurel, C. (2003). Role of a single aquaporin isoform in root water uptake. Plant Cell, 15(2), 509-522.

Kempa, S., Krasensky, J., Dal Santo, S., Kopka, J., \& Jonak, C. (2008). A Central Role of Abscisic Acid in Stress-Regulated Carbohydrate Metabolism. PLoS One, 3(12), e3935. https://doi.org/10.1371/journal. pone. 0003935

Kim, H., Lee, K., Hwang, H., Bhatnagar, N., Kim, D.-Y., Yoon, I. S., ... Kim, B.-G. (2014). Overexpression of PYL5 in rice enhances drought tolerance, inhibits growth, and modulates gene expression. J Exp Bot, 65(2), 453-464. https://doi.org/10.1093/jxb/ert397

Kudoyarova, G., Veselova, S., Hartung, W., Farhutdinov, R., Veselov, D., \& Sharipova, G. (2011). Involvement of root $\mathrm{ABA}$ and hydraulic conductivity in the control of water relations in wheat plants exposed to increased evaporative demand. Planta, 233(1), 87-94.

Mahdieh, M., \& Mostajeran, A. (2009). Abscisic acid regulates root hydraulic conductance via aquaporin expression modulation in Nicotiana tabacum. J Plant Physiol, 166(18), 1993-2003. http://dx.doi.org/10. 1016/j.jplph.2009.06.001

Murashige, T., \& Skoog, F. (1962). A Revised Medium for Rapid Growth and Bio Assays with Tobacco Tissue Cultures. Physiol Plant, 15(3), 473-497. https://doi.org/10.1111/j.1399-3054.1962.tb08052.x

Mustilli, A. C., Merlot, S., Vavasseur, A., Fenzi, F., \& Giraudat, J. (2002). Arabidopsis OST1 protein kinase mediates the regulation of stomatal aperture by abscisic acid and acts upstream of reactive oxygen species production. Plant Cell, 14(12), 3089-3099.

Osakabe, Y., Yamaguchi-Shinozaki, K., Shinozaki, K., \& Tran, L.-S. P. (2014). ABA control of plant macroelement membrane transport systems in response to water deficit and high salinity. New Phytologist, 202(1), 35-49. https://doi.org/10.1111/nph.12613

Pantin, F., Monnet, F., Jannaud, D., Costa, J. M., Renaud, J., Muller, B., ... Genty, B. (2013). The dual effect of abscisic acid on stomata. New Phytologist, 197(1), 65-72. https://doi.org/10.1111/nph.12013

Pizzio, G. A., Rodriguez, L., Antoni, R., Gonzalez-Guzman, M., Yunta, C., Merilo, E., . . Rodriguez, P. L. (2013). The PYL4 A194T mutant uncovers a key role of PYR1-LIKE4/PROTEIN PHOSPHATASE 2CA interaction for abscisic acid signaling and plant drought resistance. Plant Physiol, 163(1), 441-455. https://doi.org/10.1104/pp.113.224162

Postaire, O., Tournaire-Roux, C., Grondin, A., Boursiac, Y., Morillon, R., Schaffner, A. R., \& Maurel, C. (2010). A PIP1 aquaporin contributes to hydrostatic pressure-induced water transport in both the root and rosette of Arabidopsis. Plant Physiol, 152(3), 1418-1430. https://doi.org/10.1104/pp.109.145326

Qian, Z.-J., Song, J.-J., Chaumont, F., \& Ye, Q. (2014). Differential responses of plasma membrane aquaporins in mediating water transport of cucumber seedlings under osmotic and salt stresses. Plant, Cell \& Environment, n/a-n/a. https://doi.org/10.1111/pce.12319

Tardieu, F., Parent, B., \& Simonneau, T. (2010). Control of leaf growth by abscisic acid: hydraulic or non-hydraulic processes? Plant Cell Environ, 33(4), 636-647. https://doi.org/10.1111/j.1365-3040.2009. 02091.x

Vandeleur, R. K., Mayo, G., Shelden, M. C., Gilliham, M., Kaiser, B. N., \& Tyerman, S. D. (2009). The role of plasma membrane intrinsic protein aquaporins in water transport through roots: diurnal and drought stress responses reveal different strategies between isohydric and anisohydric cultivars of grapevine. Plant Physiol, 149(1), 445-460. https://doi.org/10.1104/pp.108.128645 
Wang, W., Yang, X., Zhang, S., \& Sun, Y. (2013). The root cortex cell hydraulic conductivity is enhanced with increasing chromosome ploidy in wheat. Plant Physiol Biochem, 68, 37-43. https://doi.org/10.1016/ j.plaphy.2013.03.021

Wang, Y., Chen, Z. H., Zhang, B., Hills, A., \& Blatt, M. R. (2013). PYR/PYL/RCAR abscisic acid receptors regulate $\mathrm{K}+$ and $\mathrm{Cl}$ - channels through reactive oxygen species-mediated activation of $\mathrm{Ca} 2+$ channels at the plasma membrane of intact Arabidopsis guard cells. Plant Physiol, 163(2), 566-577. https://doi.org/ 10.1104/pp.113.219758

Xiong, L., Ishitani, M., Lee, H., \& Zhu, J. K. (2001). The Arabidopsis LOS5/ABA3 locus encodes a molybdenum cofactor sulfurase and modulates cold stress- and osmotic stress-responsive gene expression. Plant Cell, 13(9), 2063-2083.

Zhu, C., Schraut, D., Hartung, W., \& Schäffner, A. R. (2005). Differential responses of maize MIP genes to salt stress and ABA. J Exp Bot, 56(421), 2971-2981. https://doi.org/10.1093/jxb/eri294

\section{Copyrights}

Copyright for this article is retained by the author(s), with first publication rights granted to the journal.

This is an open-access article distributed under the terms and conditions of the Creative Commons Attribution license (http://creativecommons.org/licenses/by/4.0/). 